\title{
O CONTO "ALMAS AGRADECIDAS", DE MACHADO DE ASSIS, E O PAPEL DO LEITOR
}

\author{
Valda Suely da Silva Verri \\ Secretaria Estadual de Educação do Paraná \\ Maringá (PR), Brasil
}

\begin{abstract}
Resumo: O sentido da obra machadiana, em geral, não está oferecido no nível do discurso textual e deverá ser produzido por um leitormodelo, através da sondagem das camadas profundas da linguagem. Desta forma, abordamos a organização textual do conto "Almas agradecidas", a fim de mostrar que a postura adotada pelo narrador solicita que o leitor colabore ativamente para construir uma interpretação do texto. Para tanto, ressaltamos a importância desse narrador na construção dos personagens e observamos que a sua intrusão não é estendida a todos os personagens, resultando numa proposital relativização da onisciência. Essa construção exige cooperação por parte do leitor e permite que ele atue como coautor, o qual, adotando essa postura, constitui-se num leitor-modelo para o texto.
\end{abstract}

Palavras-chave: leitor; leitor-modelo; "Almas agradecidas".

\section{The story "Almas agradecidas", by Machado de Assis, and the role of the reader}

Abstract: In general, the meanings of Machado's works are not offered in the level of textual speech. It must be produced by a modelreader, through the investigation of the deep levels of language. So, we analyze the textual organization of the narrative "Almas agradecidas", in order to show that the reader is requested to contribute in the interpretation of the text. To that extent, the narrator's attitude is extremely important for the construction of the characters and we observe that his intrusion does not in encompass all of them, which results in a deliberate relativization of omniscience. This construction demands some kind of cooperation by the reader, which allows him/her to act as a co-author. Thus, he/she becomes model-reader of the text.

Keywords: reader; model-reader; "Almas agradecidas".

Artigo recebido em 12/07/2011 e aprovado para publicação em 16/11/2011. 
Numa relação face a face - uma "relação diádica" -, ${ }^{1}$ muitas formas de reforço extralinguístico podem interferir e auxiliar na comunicação, pois os parceiros podem mutuamente se perguntar, a fim de saber se a comunicação foi estabelecida. A relação texto-leitor difere consideravelmente dessa relação, uma vez que, depois de gerado, o texto é entregue a uma variedade de atos de interpretação. No entanto, mesmo sendo a leitura do texto escrito destituída da relação face a face, os parceiros podem, seguramente, se questionar e interagir. Essa possibilidade é dada pelos "vazios" do texto, que, ao mesmo tempo em que oferecem uma falta de informação ao leitor, incitam-no a completar as informações não dadas de forma clara. Esses vazios podem também ser entendidos pelo que Umberto Eco denomina "não ditos" ${ }^{2}$ e que, segundo ele, são aquilo que não está manifesto no plano expressivo.

Machado de Assis é um escritor que, constantemente, faz uso da palavra ambígua. A leitura de seus textos não se esgota na decodificação de significante e significado, pois, em paralelo ao seu discurso linguístico, aparentemente desinteressado, existem sempre uma crítica e um questionamento do mundo que não se fazem presentes de maneira explícita.

Assim, o objetivo desta análise é, através de uma pequena amostra da obra machadiana, verificar o papel do leitor e o espaço de movimentação conferido a ele para que se estabeleça um diálogo com o texto e, mais especificamente, com o conto "Almas agradecidas". Estabelecer um diálogo com o texto pressupõe interação entre leitor e obra. Situação esta que solicita um leitor-modelo: "conjunto de condições de felicidade textualmente estabelecidas, que devem ser satisfeitas a fim de que um texto seja plenamente atualizado no seu conteúdo potencial". ${ }^{3}$ À medida que leitor e texto interagem, é promovida a dissolução da assimetria entre eles. Pretendemos, então,

\footnotetext{
${ }^{1}$ ISER, Wolfgang. A literatura e o leitor: textos de estética da recepção. Rio de Janeiro: Paz e Terra, 1979. p. 87.

${ }^{2}$ ECO, Umberto. Leitura do texto literário: lector in fabula. Trad. Mário Brito. Lisboa: Presença, 1979. p. 54.

${ }^{3}$ Idem, p. 65.
} 
mostrar que a participação ativa do leitor é imprescindível para conferir sentido ao texto machadiano.

$\mathrm{Na}$ verdade, de acordo com Umberto Eco, todo texto literário é aberto, pois possibilita uma nova visão da realidade. Parece-nos, no entanto, que a escolha de Machado de Assis por narradores que sugerem, pressupõem, revelam e ocultam indica uma intencionalidade do autor para que o discurso textual se abra para uma multiplicidade de significados que caberá ao leitor descobrir. Dessa forma, Umberto Eco e Wolfgang Iser oferecem o referencial teórico principal para o desenvolvimento desta análise das possibilidades receptivas, pois os textos machadianos são repletos de vazios, a solicitar respostas inventivas por parte do leitor.

Pretendemos ainda mostrar que a postura adotada pelo narrador é fator de especial relevância, nesse conto, pois sua intrusão auxilia o leitor a perceber possíveis significações e também a desvendar a ironia que se faz presente no texto, marca das obras machadianas. Uma vez percebida esta ironia, os textos possibilitam ao leitor uma nova visão do mundo, pois, neles, é retratada a natureza humana, com suas complexidades, as quais podem se refletir em qualquer tempo e lugar.

À medida que a narrativa caminha, o leitor poderá perceber que o narrador, em terceira pessoa, num jogo de revelação e ocultamento, descreve a índole de um dos protagonistas, deixando a do outro incompleta, para que o leitor desconfie e investigue. Essa arquitetura do texto constrói um tipo de narrador que é o autor onisciente intruso, segundo a terminologia de Norman Friedman. ${ }^{4}$ No entanto, a intrusão não é estendida a todos os personagens. Sabe-se que todo narrador funciona como uma câmera e caracteriza os personagens de acordo com o seu ponto de vista. Essa possibilidade, atribuída a todo narrador, adquire, nesse conto, relevância especial, uma vez que dela se vale o narrador para solicitar a participação do leitor, por meio de uma relativização da onisciência. Ou seja, o narrador se recusa a dar certas informações sobre um dos personagens, instalando, assim, a oportunidade de o leitor cooperar com o texto e constituir-se, dessa forma, no leitor-modelo.

Os protagonistas, Oliveira e Magalhães, são dois jovens que, após terem sido colegas de colégio, reencontram-se já adultos. $\mathrm{O}$ fato de eles terem tido destinos opostos

\footnotetext{
${ }^{4}$ MORAES, Ligia Chiappini. O foco narrativo. São Paulo: Ática, 1997. p. 26.
} 
não os impede de travar um relacionamento, tornando-se íntimos após esse reencontro. Oliveira possui uma posição social de prestígio, ao passo que Magalhães vem de uma família mais humilde e "[...] aos 16 anos achou-se só no mundo". 5

A leitura desse conto nos leva a observar a profundidade psicológica dos personagens de Machado de Assis e ver que o importante, em seus textos, não é a história narrada, mas a reflexão que esta pode propiciar acerca do meio social das personagens e das convenções desse meio - que, metaforicamente, é sempre o nosso independentemente de tempo e lugar. Assim explica Alfredo Bosi, em relação à obra machadiana: "[...] a atitude e os gestos, entre os indivíduos, serão sempre os mesmos, mas os efeitos podem ser colhidos de maneira diferente conforme a índole, o espírito e as tendências do observador". 6

Nesse sentido, o papel do narrador é fator de extrema importância, tanto nesse conto como em toda a obra machadiana. Além de ser o observador e organizador dos fatos, sua intrusão contribui para constituir a abertura do texto, determinando o papel do leitor-modelo. Tal contribuição se dá à medida que o processo de constituição do discurso do narrador, constantemente, solicita a consciência imaginativa do leitor para participar ativamente, no sentido de completar aquilo que ele não diz claramente.

Algumas considerações feitas por Iser esclarecem o que ocorre na linguagem da obra de arte e podem, efetivamente, ser aplicadas a esse conto:

O processo de comunicação assim se realiza, não através de um código, mas sim através da dialética movida e regulada pelo que se mostra e se cala. $\mathrm{O}$ que se cala impulsiona o ato de constituição, ao mesmo tempo que este estímulo para a produtividade é controlado pelo que foi dito, que muda de sua parte quando se revela o que fora calado. $^{7}$

Iser manifesta, assim, a natureza multívoca do texto, o qual é um organismo que solicita de seu leitor uma resposta criadora àquilo que a obra não diz, mas evoca, sugere. E, em se tratando de um conto de Machado de Assis, que faz uso predominante

\footnotetext{
${ }^{5}$ ASSIS, Machado de. Contos. Seleção de Deomira Stéfani. 9. ed. São Paulo: Ática, 1982. p. 13.

${ }^{6}$ BOSI, Alfredo. Machado de Assis. São Paulo: Ática, 1982. p. 370.

${ }^{7}$ ISER, Wolfgang. A literatura e o leitor: textos de estética da recepção, cit., p. 90.
} 
da palavra reticente, ambígua, a intervenção do leitor é imprescindível para que a narrativa revele toda a amplitude de sua riqueza estética. Esta colaboração interpretativa faz parte da própria organização do texto machadiano.

O narrador de Machado de Assis também é assim explicado por Sônia Brayner:

A ótica da relatividade é a posição preferida para seus narradores: colocados no seu mundo particular, olham e julgam o que os envolve como duplos, atores/autores sempre atentos a comentar, ironizar e se apropriar em benefício próprio das instâncias discursivas do contexto. ${ }^{8}$

Como foi dito, temos aqui um autor onisciente intruso. Esse tipo de narrador, segundo Moraes, é comum nos textos de Machado de Assis e contribui para a construção de uma ficção que rompe com a verossimilhança. Segundo ela:

[...] Machado, antecipando vertentes ultramodernas, utiliza esse narrador intruso como ruptura da verossimilhança. Seu leitor não se esquece de que está diante de uma ficção, de uma análise, da interpretação ficcional da realidade, um mero ponto de vista, sobre pessoas, acontecimentos, sociedade, lugar e tempo. ${ }^{9}$

Como consequência dessa ruptura, proporcionada pelo comportamento do narrador, o leitor, assumindo a postura de leitor-modelo, terá condições de julgar o que lê sem se envolver emocionalmente com os personagens. A postura do narrador em relação àquilo que narra possibilita ao leitor certo distanciamento, para que ele possa adotar atitudes interpretativas diante das intenções virtualmente possibilitadas pelo texto. No conto em questão, podemos notar a intrusão do narrador em vários trechos, como: "Facilmente acreditará o leitor que estes dois amigos se fizessem confidentes de todas as coisas, principalmente de coisas de amores.", ${ }^{10}$ ou "Não desejava exagerar aos

\footnotetext{
${ }^{8}$ BRAYNER, Sônia. Labirinto do espaço romanesco. Rio de Janeiro: Civilização Brasileira, 1979. p. 7172.

${ }^{9}$ MORAES, Ligia Chiappini. O foco narrativo, cit., p. 29. Grifos da autora.

${ }^{10}$ ASSIS, Machado de. Contos, cit., p. 16.
} 
olhos dos leitores a beleza da moça, que a um namorado parece sempre maior do que realmente é." ${ }^{11}$

O comportamento descrito por Moraes faz-se presente no discurso desse narrador, possibilitando ao leitor despertar para o diálogo entre narrador e narratário. Este último, em síntese, representa, como bem explicam Reis e Lopes: "[...] uma entidade fictícia, um 'ser de papel' com existência puramente textual, dependendo diretamente de outro 'ser de papel' com existência puramente textual, o narrador que se lhe dirige de forma expressa ou tácita". ${ }^{12}$ Assim, o diálogo entre narrador e narratário, nesse conto, não cumpre apenas uma função estrutural, mas também possibilita analisar o narrado, para que o leitor possa desconfiar, não se identificando emocionalmente com os personagens e suas ações. O narrador está sempre lembrando ao leitor o caráter ficcional do texto.

Essa postura do narrador de Machado rompe com a ilusão de realidade pretendida pelos escritores do período realista, que tentavam retratar a vida de maneira objetiva, aproximando-se dos pressupostos científicos do século XIX. Machado, diferentemente, vai deixar transparecer um realismo que se define no sentido exato da palavra, pois se utiliza de um narrador que, durante todo o tempo, convida o leitor a penetrar no texto e a sair dele, enfim, a vê-lo com olhos críticos. Antônio Cândido se manifesta em relação a essa tendência machadiana, que o distingue dos demais escritores de seu tempo, da seguinte forma:

Não é nos apaixonados naturalistas de seu tempo, teóricos da objetividade, que encontramos o distanciamento estético que reforça a vibração da realidade, mas sim na sua técnica de espectador. ${ }^{13}$

A interação entre texto e leitor, nesse conto, solicita ainda que o leitor perceba essa intrusão do narrador como um chamariz para a fruição dos efeitos estéticos do texto. O leitor-modelo perceberá, então, que há uma deliberada relativização da onisciência. Vejam-se as referências a Magalhães: "Os vinhos eram bons; Magalhães

\footnotetext{
${ }^{11}$ Idem, p. 20.

${ }^{12}$ REIS, Carlos; LOPES, Ana Cristina. Dicionário de teoria da narrativa. São Paulo: Ática, 1988. p. 66. Grifos dos autores.

${ }^{13}$ CANDIDO, Antonio. Vários escritos. São Paulo: Duas cidades, 1970. p. 22.
} 
gostava de vinhos bons", ${ }^{14}$ ou "Era Magalhães um rapaz de agudo espírito, boa observação, conversador ameno, um pouco lido em obras fúteis e correntes". ${ }^{15}$

Nota-se que o narrador tem condições de descrever aspectos íntimos do personagem Magalhães, mas que, no entanto, relativiza a onisciência no que diz respeito ao modo como focaliza este personagem. O narrador simplesmente se recusa, durante todo seu percurso narrativo, a dizer o que Magalhães pretende em relação a Oliveira, embora se saiba que ele é capaz de fazê-lo, dada sua onisciência. Desse modo, só revela aquilo que lhe convém, deixando a oportunidade para o leitor, através de movimentos cooperativos, intervir, completando aquilo que não diz.

Quanto a Oliveira, o leitor sabe tudo o que ele pensa, inclusive o que quer de Magalhães, pois essa informação o narrador lhe dá claramente por meio do enunciado: "Finalmente, o seu ex-colega já lhe confiara no trajeto do escritório ao hotel, o que não contava a um amigo debaixo do sol. Oliveira queria ser esse amigo". ${ }^{16}$

Destacamos ainda a preocupação de Oliveira com o amigo, claramente exposta ao leitor, quando Magalhães ficou desempregado. A atitude mostra que ele nutria uma amizade sincera por Magalhães: "Durante a noite seguinte, meditou Oliveira acerca do negócio de Magalhães". ${ }^{17}$

São estes alguns dos momentos em que o leitor-modelo tem a oportunidade de perceber que há outras intenções por parte do narrador. Se ele é onisciente em relação aos dois personagens, por que, então, não revela, de igual maneira, tudo o que um pensa em relação ao outro, reservando-se a apenas um deles? Tal "arrumação" do texto é capaz de chamar a atenção do leitor para que ele levante questionamentos, estabelecendo, assim, o referido diálogo com o texto.

Vemos, então, que o espaço para a movimentação do leitor, nesse conto, é amplo. Sua tarefa não se esgota em decodificar o código linguístico e distrair-se com a história, a qual nem é tão sedutora, e, por si, relativamente incapaz de chamar a atenção. Vemos também que a beleza do texto se encontra justamente nessa atmosfera sugestiva

\footnotetext{
${ }^{14}$ ASSIS, Machado de. Contos, cit., p. 15.

${ }^{15}$ Ibidem.

${ }^{16}$ Ibidem.

${ }^{17}$ Idem, p. 18.
} 
da linguagem, a qual, não sendo captada pelo leitor, poderá tornar o texto aparentemente banal.

Assim, a tessitura do conto requer a ativa inserção do leitor em seu domínio e a consequente recapitulação de suas propriedades de modo reinventivo, pois o texto se apoia em uma série de códigos que se destinam a produzir efeitos estéticos. Mas a sua perfeita arquitetura não está somente no fato de o narrador não revelar o que Magalhães pretende em relação a Oliveira e em solicitar que o leitor coopere nesse sentido. O narrador, além de não penetrar, da mesma maneira, no pensamento dos dois personagens, tenta, ainda, manter a ilusão de que o faz. Ou seja, um leitor desatento pode se iludir achando que ele revela o pensamento dos dois rapazes, mostrando que ambos eram realmente amigos. $\mathrm{O}$ trecho seguinte alude a essa postura:

Despediram-se na esquina da rua do Lavradio, e Oliveira enfiou pela de S. Jorge. Ambos foram pensando um no outro.

- Parece ser um excelente rapaz este Magalhães, dizia o jovem advogado consigo; no colégio foi sempre um menino sério. Ainda o é agora, e até parece um pouco reservado, mas é natural porque sofreu.

Três dias depois, apareceu Magalhães no escritório de Oliveira; falou na sala a um porteiro que lhe pediu o cartão. ${ }^{18}$

Apesar de o narrador dizer que ambos foram pensando um no outro, o leitormodelo poderá perceber que ele só desvenda os pensamentos de Oliveira e, em seguida, muda de assunto, passando a narrar a ida de Magalhães ao escritório de Oliveira. Em outras palavras, ao mesmo tempo em que ele dá a entender que está dizendo tudo sobre os dois personagens, parece esperar que o leitor perceba algo incompleto: as intenções de Magalhães em relação a Oliveira. Esse comportamento do narrador vai se estender por toda a narração. O leitor só tem, então, condições de saber que objetivo tem Magalhães, na sua amizade com Oliveira, por meio de suas ações.

Pode-se, portanto, entender como irônico o padrão de amizade mostrado nesse conto. Para tanto, relembremos o conceito de ironia oferecido por Sônia Brayner:

Trabalho teórico e, mais amplamente, semiótico, a ironia, como todo fenômeno de humor, prefere um significante não habitual, menos

\footnotetext{
${ }^{18}$ Idem, p. 13-14.
} 
provável, através do qual instala seu coeficiente de incerteza. Nem transparente em demasia, pois seu caráter artificioso estaria imediatamente decodificado, nem opaco, tampouco, prefere estabelecer uma relação de translucidez [...]. ${ }^{19}$

Isso se faz notar principalmente quando o narrador, por várias vezes, refere-se às ações de Magalhães empregando a palavra "dedicação": "A dedicação de Magalhães também parecerá condescendente aos espíritos mais severos", ${ }^{20}$ ou "Era ocasião de manifestar a dedicação de Magalhães", ${ }^{21}$ ou ainda "A doença de Oliveira era grave; durante todo o tempo que durou, não desmentiu nunca a dedicação de Magalhães". ${ }^{22}$

O uso dessa palavra pode ser entendido como uma ironia, uma vez que as ações de Magalhães demonstram o contrário do que se espera de um amigo dedicado. Ele age em causa própria, pois se aproveita de Oliveira para conquistar a amizade de pessoas que fazem parte de uma camada social de prestígio. Aproveita-se do amigo ainda para conseguir um bom emprego, pois Oliveira era uma pessoa influente. Finalmente, vale-se de Oliveira para conseguir o casamento que lhe asseguraria, definitivamente, a ascensão social, o que consuma o "roubo" maior. Nesse sentido, o texto exige que o leitor se empenhe na tarefa interpretativa e dote de significado aquilo que não foi empregado com objetividade. Confirma-se, desse modo, que o processo de constituição do texto privilegia a importância do papel ativo do leitor como seu coprodutor.

Por fim, já num dos últimos parágrafos do conto, o narrador acaba por declarar que, deliberadamente, não penetra nos pensamentos de Magalhães para dizer suas intenções: "Magalhães não ajuntou nenhum substantivo a esse adjetivo. Não nos é dado perscrutar o seu pensamento interior. Caíram os dois amigos nos braços um do outro com grandes exclamações e protestos". 23

Um leitor experiente poderá, no entanto, perceber que o narrador só admite e declara esse fato depois de tudo consumado, ou seja, depois de o personagem já ter

\footnotetext{
${ }^{19}$ BRAYNER, Sônia. Labirinto do espaço romanesco, cit., p. 100.

${ }^{20}$ ASSIS, Machado de. Contos, cit., p. 23. Grifos nossos.

${ }^{21}$ Idem, p. 27. Grifos nossos.

${ }^{22}$ Ibidem. Grifos nossos.

${ }^{23}$ Idem, p. 30.
} 
conseguido tudo o que pretendia e, por consequência, o leitor já pôde descobrir quais eram as intenções dele. Há, nesse trecho, portanto, mais um parágrafo carregado de ironia, pois o narrador conhece as intenções do personagem e já deu condições também ao leitor de percebê-las. No entanto, no nível do código linguístico, afirma o contrário.

Parece-nos, então, que o narrador tenta, mais uma vez, atrair a atenção do leitor, pois, se este ainda não conseguiu perceber que as intenções do personagem não são perscrutadas durante todo o texto e não só no trecho aqui em questão, ele está tendo uma última oportunidade de fazê-lo. Isso quer dizer que o leitor é ajudado pelo texto, para que possa dialogar com ele. A construção narrativa desse conto vem, assim, confirmar a afirmação de Eco de que: "[...] prever o leitor-modelo não significa apenas 'esperar' que exista, significa também conduzir o texto de forma a construí-lo. Um texto não se limita a apoiar-se sobre uma competência, contribui para a produzir". ${ }^{24}$

De fato, o leitor não tem um confortável acesso às intenções de Magalhães. No entanto, o texto dá pistas para que se possam perceber essas intenções. Efetivamente, o que está dito no enunciado, sutilmente, encaminha o leitor a conhecer a índole de Magalhães. Observemos dois trechos em que ele se revela materialista e interesseiro: "[...] o rapaz sem guarda-chuva deitou um rápido olhar ao seu companheiro, espécie de exame prévio da condição social da pessoa. Parece que a achou boa, porque aceitou o convite". ${ }^{25}$ E ainda: "[...] não me há de censurar, porém, que eu procure ver o lado prático das coisas; um coração de ouro vale muito, mas um coração de ouro com ouro vale mais". ${ }^{26}$

Para além dos trechos citados, há um momento em que Magalhães chega até a esboçar certo cinismo, quando, ao ficar desempregado, recebe a oferta de ajuda de Oliveira com as seguintes palavras: "[...] dia virá em que eu possa vencer a má fortuna de uma vez para sempre. Tenho o remédio nas mãos" ${ }^{27}$ Pode-se crer que o remédio a que se refere seja o próprio amigo.

\footnotetext{
${ }^{24}$ ECO, Umberto. Leitura do texto literário: lector in fabula, cit., p. 59.

${ }^{25}$ ASSIS, Machado de. Contos, cit., p. 12.

${ }^{26}$ Idem, p. 20.

${ }^{27}$ Idem, p. 17. Grifos nossos.
} 
Caberá, portanto, ao leitor realizar os "movimentos cooperativos ativos e conscientes", ${ }^{28}$ pois os "vazios" não preenchidos poderão reter o leitor numa visão superficial, que o fará entender os acontecimentos narrados como simples obra do acaso. Nesse caso, Magalhães seria visto como um grande amigo de Oliveira que, involuntariamente, acabou se apaixonando por sua namorada. Uma espécie de "diletante artístico", ${ }^{29}$ de que fala Iser, ou seja, um leitor interessado apenas nas ações dos seres representados, poderia entender todas as vantagens que Magalhães tirou dessa amizade como ajuda espontânea de Oliveira. O leitor disposto a colaborar com a narrativa, diferentemente, compreenderá as ressonâncias significativas potencialmente contidas na obra e perceberá o caráter irônico existente nas palavras "amigo", "amizade" etc., dentro desse texto. Temos aqui um tema amplamente explorado por Machado de Assis: o conflito entre aparência e essência. Destacamos ainda a frase final do conto: "Foram amigos até a morte." 30

Na realidade, o texto mostra a mente humana, cheia de complexidades que, em nome das convenções sociais, nem sempre são reveladas. Magalhães, apesar de seus atos, continua sendo uma pessoa benquista perante a sociedade e até pelo próprio Oliveira, pois sua hipocrisia, despercebida, fica abafada pelo "bom tom".

Esse conto propõe, assim, ao leitor, um questionamento das verdades contidas nas situações sociais e na mente humana. Para Brayner, Machado de Assis utiliza-se da ironia como "arma de descoberta do ridículo camuflado nas situações equívocas". ${ }^{31}$ Assim, a fruição dos efeitos estéticos desse conto, mesclado de ironia, requer como imprescindível a instalação do "mundo do texto", que constitui o ato de criação artística. Nota-se que a crítica social se faz presente de maneira velada, sutil, a ser percebida por um leitor competente. Alfredo Bosi comenta a crítica social presente na obra machadiana:

O princípio, hoje tão proclamado pelos que não se enquadram nos postulados do materialismo histórico, de que a literatura transcende

\footnotetext{
${ }^{28}$ ECO, Umberto. Leitura do texto literário: lector in fabula, cit., p. 54.

${ }^{29}$ ISER, Wolfgang. A literatura e o leitor: textos de estética da recepção, cit., p. 97.

${ }^{30}$ ASSIS, Machado de. Contos, cit., p. 30.

${ }^{31}$ BRAYNER, Sônia. Labirinto do espaço romanesco, cit., p. 104.
} 
objetivos políticos e partidários, de que a arte interessada a serviço de uma ideia ou de uma causa é incompatível com a verdadeira missão do artista, tudo isso que vemos afirmar frequentemente, nas entrevistas de alguns maiores escritores da atualidade, era o que Machado realizava na linha harmoniosa e magnífica de sua obra impar. ${ }^{32}$

De fato, a censura a valores cristalizados pela sociedade se faz presente na obra de Machado de maneira sutil, feita através daquilo que não se diz, mas que sugere, pressupõe, evoca. O texto não perde seu caráter artístico, pois essa crítica não aparece como seu objetivo primordial.

Tendo em vista que o texto produz as reflexões mencionadas até aqui, pode-se afirmar que a leitura desse conto mostra a seu intérprete um novo conceito de mundo. Isso se dá não no nível discursivo, mas pela decisão interpretativa adotada pelo leitor. Essa decisão é influenciada por um conjunto de elementos que o leitor traz consigo, em sua situação cultural.

Desse modo, sendo o conto "Almas agradecidas" um texto aberto, ${ }^{33}$ por permitir a intervenção do leitor no ato de leitura, há também que se considerar as experiências do leitor em relação a outros textos. Em outras palavras, seguramente, as informações que o leitor já possui acerca de certas situações narrativas o auxiliam em suas decisões interpretativas.

Julia Kristeva reflete que:

\begin{abstract}
A linguagem poética surge como um diálogo de textos: toda sequência se constrói em relação a uma outra, provinda de um outro corpus, de modo que toda sequência está duplamente orientada: para o ato de reminiscência (evocação de uma outra escrita) e o ato de intimação (a transformação dessa escritura). ${ }^{34}$
\end{abstract}

Segundo ela, todo texto dialoga com outros textos, sejam do mesmo autor ou não, sejam contemporâneos a ele ou não. Nesse sentido, quanto mais familiaridade tiver o leitor com a linguagem literária, mais facilmente se fará a interação entre ele e o texto.

\footnotetext{
${ }^{32}$ BOSI, Alfredo. Machado de Assis, cit., p. 364-365.

${ }^{33}$ ECO, Umberto. Obra aberta. 8. ed. Trad. Giovani Cutolo. São Paulo: Perspectiva, 1991.

${ }^{34}$ KRISTEVA, Júlia. Introdução à semanálise. São Paulo: Perspectiva, 1974. p. 98. Grifo da autora.
} 
As leituras anteriores facilitam a fruição dos efeitos estéticos através do reconhecimento dos quadros intertextuais, que nada mais são do que "[...] esquemas retóricos e narrativos que fazem parte de um repertório selecionado e restrito de conhecimentos que nem todos os membros de uma dada cultura possuem". ${ }^{35}$

Essa capacidade de reconhecer os quadros intertextuais, que possibilitam ao leitor experiente, por vezes, julgar banal, num texto, aquilo que a um leitor comum causaria surpresa, constitui a "competência intertextual", que "[...] compreende todos os sistemas semióticos familiares ao leitor". ${ }^{36}$

Se todo texto prevê um leitor-modelo, que é a linha de seu horizonte de criação, é necessário que esse leitor esteja, de certa forma, sintonizado com o repertório utilizado pelo autor. Assim, um leitor já familiarizado com a obra de Machado de Assis, com seu estilo irônico de retratar o mundo, mais facilmente realizará as inferências necessárias para cooperar com o conto "Almas agradecidas". As diferentes posições que, então, autor e leitor ocupam no texto são estratégias textuais, pois, da mesma maneira que o autor se moveu generativamente, deve também o leitor participar ativamente. Ler esse texto não é, portanto, centrar-se no incidente da fábula, mas sim em torno do comportamento e dos sentimentos dos personagens, pois eles encaminham o leitor para um objetivo maior, o questionamento do mundo. Como vimos, o narrador do conto dá algumas informações e oculta outras, deixando para o leitor a tarefa de perceber ou não esse jogo, o que o caracteriza ou não como leitor-modelo.

Esperamos ter esclarecido a questão fundamental que norteou este trabalho, que foi o papel do leitor no conto "Almas agradecidas". Percebemos, por fim, que o prazer que esse texto pode proporcionar ao leitor, quando se consegue desvendar a ironia contida no seu conteúdo, faz perceber que a realidade retratada por Machado é vista por uma lógica às avessas. Entenda-se a expressão "às avessas" não só como contrário, mas também como interior, ou seja, a real natureza das coisas. A obra machadiana está a revelar, constantemente, que a essência das coisas se encontra na mente humana, complexa, cheia de cavidades escuras e impenetráveis, a qual nem sempre se adapta ao mundo exterior, tampouco corresponde sempre àquilo que a

\footnotetext{
${ }^{35}$ ECO, Umberto. Leitura do texto literário: lector in fabula, cit., p. 88.

${ }^{36}$ Idem, p. 86.
} 
sociedade espera dela. Esse é o avesso, e é o que realmente importa em seus textos, uma vez que a história narrada se apresenta apenas como um meio para veicular tais conceitos essenciais.

O conto analisado apresenta-se como um meio de desmascarar situações hipócritas, forjadas em favor do desejo de ascensão social. Para tanto, a figura do narrador é extremamente marcante. Essas inversões e dissonâncias é que fazem a grandiosidade do texto, e é fundamental que sejam percebidas para que haja interação e a consequente dissolução da assimetria entre texto e leitor. Assim, saborear esse conto, ou qualquer outro texto machadiano, requer do leitor uma postura crítica, uma vez que o leitor é induzido a criar e não apenas a observar. Ao perceber as contradições e paradoxos inerentes ao próprio ato de viver, apontadas por meio de uma inversão dos valores consagrados pelo meio social que retrata, revela-se uma concepção de realidade. Revela-se também que os anseios humanos são subjetivos e nem sempre coincidem com os do mundo externo ao homem, com aquilo que a sociedade imagina e espera de cada um. É imprescindível que o leitor perceba a coexistência desses opostos, os quais não estão expressos na superfície do texto, mas devem ser captados através da "transposição" da matéria narrativa. O que se manifesta de Machado, nesse texto, é seu estilo irônico, disfarçado sob a forma de conformidade indiferente.

Referências:

ASSIS, Machado de. Contos. Seleção de Deomira Stéfani. 9. ed. São Paulo: Ática, 1982.

BOSI, Alfredo. Machado de Assis. São Paulo: Ática, 1982.

BRAYNER, Sônia. Labirinto do espaço romanesco. Rio de Janeiro: Civilização Brasileira, 1979.

CANDIDO, Antonio. Vários escritos. São Paulo: Duas cidades, 1970.

ECO, Umberto. Leitura do texto literário: lector in fabula. Trad. Mário Brito. Lisboa: Presença, 1979.

ECO, Umberto. Obra aberta. 8. ed. Trad. Giovani Cutolo. São Paulo: Perspectiva, 1991. 
ISER, Wolfgang. A literatura e o leitor: textos de estética da recepção. Rio de Janeiro: Paz e Terra, 1979.

KRISTEVA, Júlia. Introdução à semanálise. São Paulo: Perspectiva, 1974.

MORAES, Ligia Chiappini. O foco narrativo. São Paulo: Ática, 1997.

REIS, Carlos; LOPES, Ana Cristina. Dicionário de teoria da narrativa. São Paulo: Ática, 1988.

Valda Suely da Silva Verri é graduada em Letras pela Universidade Estadual de Maringá, especialista em Literatura e Ensino pela Universidade Estadual de Maringá, mestre em Letras - Estudos Literários pela Universidade Estadual de Londrina e doutora em Letras - Estudos Literários Universidade Estadual de Londrina. Tem experiência docente no Ensino Fundamental, no Médio e no Superior (no curso de Letras, em Teoria da Literatura e Literatura Brasileira). Publicou nas revistas Aletria (UFMG), Linguagem \& Ensino (UCPel), e Revista da ANPOLL, entre outras. E-mail: <vsverri@yahoo.com.br>

Recebido: $12 / 07 / 2011$

Aprovado: 16/11/2011 